\title{
Grupo focal e prática de pesquisa em Análise do Discurso: metodologia em perspectiva dialógica
}

\section{Focus groups and research practices in Discourse Analysis: methodology in perspective}

Poliana Coeli Costa Arantes

UERJ

polianacoeli@yahoo.com.br

Bruno Deusdará

UERJ

brunodeusdara@gmail.com

Resumo: Este texto propõe uma discussão a respeito dos impasses metodológicos com os quais um analista do discurso se confronta ao optar pelo acesso aos "dados" por meio de pesquisa de campo. Serão apresentadas reflexões sobre a produção e análise de "dados" em contextos de interação e, finalmente, exemplificações do percurso metodológico em pesquisa que investiga o universo da prática de leitura por meio da realização de grupos focais.

Palavras-chave: pesquisa de campo; grupo focal; Análise do Discurso.

Abstract: The aim of this paper is to introduce a discussion about the methodological impasses that a discourse analyst confronts accessing the "data" through the methodology of field research. We will show reflections on the production and analysis of "data" in interaction contexts and exemplifications of the methodological course in a research that investigates the reading practices using the method of focus groups.

Keywords: field research; focus group; discourse analysis.

Recebido em: 21 de julho de 2015.

Aprovado em: 07 de março de 2016. 


\section{Introdução}

Neste texto propomos um diálogo com um projeto mais geral de afirmação das práticas de pesquisa qualitativa, que vem atravessando, mais recentemente, diferentes áreas das ciências humanas. Ao mesmo tempo, desejamos explicitar as ferramentas de que dispomos como analistas do discurso para esse debate, aliando-as a uma postura ética, orientada por uma valorização do próprio processo de pesquisa em detrimento de uma espécie de fetichismo dos resultados.

O referido projeto de afirmação das práticas de pesquisa encontra inspirações diversas, respondendo a aspectos de diferentes ordens da conjuntura nacional atual: (i) de ordem econômica, remetendo ao desequilíbrio entre as áreas na destinação dos recursos públicos para o financiamento de pesquisa; (ii) social, interrogando as forças que atuam na compressão do espaço público e de um deslocamento no papel do intelectual; (iii) cultural, fundado em um preconceito insistente baseado em dicotomias como teoria $\times$ prática, objetivo $\times$ subjetivo; (iv) institucional, apreensível nas pretensões por demarcação de fronteiras e manutenção de especialismos; (v) tecnológico, cuja aceleração e imediaticidade no acesso à informação parece atribuir aos saberes efeitos de intensa fragmentação e rápida obsolescência; (vi) filosófica, na afirmação de uma perspectiva que compreende a indissolúvel vinculação entre saberes e as relações de poder em sua emergência; (vii) científica, nos debates em torno da legitimidade e validade de saberes produzidos em percursos que não pressupõem reiterar imparcialidades ou universalismos.

Esse cenário nos indica a necessidade de um intenso debate, movimentando atores em diferentes instâncias, atuando ora em propósitos convergentes, ora em divergências cujas soluções não parecem despontar tão facilmente. Entendemos que nossa inserção no referido debate pode apontar para interrogações relativas às questões gerais, mas também precisa se centrar nas experiências concretas nas quais temos investido como analistas do discurso.

Procurando compreender o modo como analistas do discurso podem se inserir nesse debate, parece-nos relevante observar que, de certo modo, essa parece ser uma atitude reiterada desde a emergência desse campo do saber no âmbito dos estudos linguísticos. Isso é o que destacam Mariani e Medeiros (2013), quando ressaltam que a descontinuidade operada pela Análise do Discurso (AD) em relação 
aos estudos linguísticos nos anos 1970 e 1980, no Brasil, produziu um "acontecimento teórico".

Ainda em diálogo com as autoras, desde seus movimentos inaugurais, os estudos do discurso se propõem a considerar que "falar é tomar posição no sócio-histórico, é inscrever-se subjetivamente em redes de sentidos com a ilusão de se estar na origem e no controle do dizer" (Ibid., p. 20).

Se desde seu gesto inaugural a AD vem fortalecendo a evidência dos vínculos indissolúveis entre ciência e política, uma contribuição contemporânea que nos parece importante atua no sentido de apontar para a necessária dissolução da crença nos universalismos, indicando um projeto de mudança social implicado na explicitação do potencial de intervenção dos dispositivos de pesquisa.

Com efeito, toda pesquisa produz intervenção no cenário em relação ao qual pretende investigar. Não há ato de conhecer que não produza deslocamentos, ainda que em escala infinitesimal. Nosso projeto passa por uma reflexão acerca das práticas metodológicas, de modo que seja possível acolher, o que nos acontece durante a pesquisa, tudo aquilo que reafirma sua dimensão processual, em detrimento da busca exclusiva por resultados em razão unicamente de objetivos previamente estabelecidos.

Um projeto de atuação em $\mathrm{AD}$ assim formulado está em consonância com um desejo de contribuir "no sentido de fazer implodirem as visões totalizantes sobre o real, possibilitando repensar os grandes estereótipos com os quais convivemos", bem como "no sentido de desnaturalizar o que pode efetivamente ser apreendido como efeito discursivo" (ROCHA, 2014, p. 629).

Como percurso para as reflexões propostas, partiremos de uma breve consideração a respeito das opções metodológicas em pesquisa qualitativa, buscando caracterizar suas especificidades; em especial, os desafios colocados quando o pesquisador vai a campo. Para evitar uma ênfase excessiva sobre o dito, negligenciando os modos de dizer e as práticas subjacentes aos textos, é preciso refletir sobre o contexto institucional no qual a pesquisa se insere. Com isso, evita-se a ideia de que comparecem à situação apenas pesquisadores e participantes da pesquisa. Essas imagens remetem a apenas uma das espessuras da densidade institucional na qual o pesquisador se insere. 
Este texto propõe uma discussão a respeito dos impasses metodológicos com os quais analistas do discurso se confrontam ao eleger dispositivos diversos de pesquisa de campo como fonte de acesso ao que habitualmente se designa por "dados" a serem submetidos a exame. Centramos nossas reflexões no debate acerca do percurso metodológico em pesquisa que investiga o universo da prática de leitura por meio da realização de grupos focais com leitores de dois universos sócio-culturais diferentes, o alemão e o brasileiro ${ }^{1}$.

Como considerações finais, ressaltamos o modo segundo o qual se pode privilegiar uma dinâmica processual das pesquisas em detrimento dos resultados atingidos, considerando a possibilidade de incorporação dos imprevisíveis, das contingências dos processos em detrimento dos resultados.

\section{Práticas metodológicas e a afirmação da dimensão processual em pesquisa linguística}

Discutimos a seguir as práticas metodológicas em pesquisa qualitativa, ressaltando a rejeição a roteiros previamente estabelecidos como elemento sem o qual se suporia ser possível questionar sua cientificidade. Em termos bastante superficiais, pode-se compreender nesse tipo de consideração acerca de uma suposta fragilização de "resultados", quando não se segue um roteiro metodológico fixo, um diálogo com um projeto foucaultiano de genealogia. A questão que dirige esse projeto é a seguinte: o que se reivindica quando se pretende afirmar acerca de um conhecimento que ele seja científico? Relacionando-a com o que apresentamos aqui, é adequado interrogar: que legitimidade se deseja conferir aos resultados de pesquisa quando se exige que sejam obtidos por roteiros metodológicos fixos?

Sendo assim, situamos essa expectativa de cientificidade subjacente às orientações conferidas às práticas metodológicas, inicialmente buscando referências básicas no campo dos estudos

\footnotetext{
${ }^{1}$ Esta pesquisa foi realizada no Programa de Pós-graduação em Estudos Linguísticos da Faculdade de Letras da Universidade Federal de Minas Gerais, orientada pelo prof. Dr. Wander Emediato, com período de bolsa de doutorado sanduíche na AlbertLudwigs-Univesität Freiburg (Alemanha), sob a orientação do prof. Dr. Rolf Kailuweit, financiada pela CAPES e pelo DAAD.
} 
linguísticos. Em seguida, recorremos a elementos que buscam caracterizar o dispositivo do grupo focal para acesso aos "dados" na pesquisa de campo. Por último, explicitamos aspectos que vêm fundamentando as reflexões sobre o potencial de intervenção implicado em qualquer pesquisa, não apenas nas de natureza qualitativa. Damos destaque ao privilégio da própria dimensão processual da pesquisa e a legitimidade reivindicada por esse tipo de discussão.

\section{O "paradoxo do pesquisador" e a impossibilidade do apagamento de sua inscrição no campo}

No campo dos estudos linguísticos, parece-nos lícito remontar às experiências empreendidas por W. Labov (2008) como um momento inaugural em que se pretendeu refletir explicitamente sobre a presença do pesquisador no campo. As preocupações inicialmente estabelecidas - ainda que de uma maneira ou de outra talvez permaneçam presentes em certas recomendações que insistem em se oferecer a pesquisadores da área - serão aqui assumidas como remetendo a uma perspectiva que respondia a impasses de sua época. Sua reflexão fundamentou-se no que se convencionou chamar de "paradoxo do observador", cuja síntese seria a seguinte: o projeto de uma pesquisa de campo "deve ser descobrir como as pessoas falam quando não estão sendo sistematicamente observadas - no entanto, só podemos obter tais dados por meio de observação sistemática" (Ibid., p. 244).

A delimitação do referido paradoxo emerge como uma advertência para um problema que se deseja superar, nos marcos de uma orientação de pesquisa que privilegia a análise estatística de dados. Há, como se vê, uma pretensão de observação da fala espontânea, que a presença do pesquisador viria, senão inviabilizar, no mínimo, suspender. Sem que se discuta exatamente essa pretensão de acesso à espontaneidade, observando com que projeto de fazer ciência ela dialoga, as orientações pretendem neutralizar os efeitos da presença do pesquisador, em busca de restituir a espontaneidade da fala. Esse projeto de apagamento da inscrição do pesquisador surge como efeito do tipo de saber pretendido, extraído de variáveis estatísticas. No paradoxo, a pretensão de acesso à espontaneidade encontraria sua dificuldade no fato de só poder ser apreensível por meio da sistematicidade da observação. 
As alternativas oferecidas nessa direção seriam, de um lado, desenvolver procedimentos diversos com o intuito de desviar a atenção dos falantes, permitindo, ao menos supostamente, que "a pessoa presuma inconscientemente que, naquele momento, não está sendo entrevistada" (Ibid., p. 245) e, de outro, realizar, depois de entrevistas individuais, sessões em grupo, nas quais os participantes interagiriam entre si. A conclusão a que se chegou com tal procedimento sintetiza-se da seguinte forma: "como resultado, reduziu-se ao mínimo o efeito da observação sistemática" (loc. cit.).

Sem dúvida, a pretensão de apagamento da presença do pesquisador no campo é apenas parte de um projeto de fazer ciência com o qual uma perspectiva discursiva tem estabelecido polêmicas importantes. Apenas destacaríamos aqui o fato de tais polêmicas produzirem como efeito a ausência de roteiros metodológicos fixos, por assumir uma perspectiva acerca dos eventos sociais que não pode sustentar a ideia de que haveria uma espontaneidade sem espessura histórica. Essa ausência é eventualmente indicada como um demérito, cujo risco recairia sobre a perda de validade científica dos resultados alcançados. Já entre os pesquisadores do campo do discurso, somamo-nos aos que consideram que essa ausência, longe de figurar como um demérito que fragilizaria os resultados, aponta para uma impossibilidade de dissociação entre teoria e prática de pesquisa.

Aliás, trata-se de um dos aspectos fundadores do campo dos estudos do discurso a crítica ao descolamento das práticas metodológicas em relação à perspectiva teórica. Já no texto de 1969, Pêcheux, ainda assinando como Paul Henry, apontava nessa direção indicando que toda teoria pressupõe igualmente a (re)invenção de seus instrumentos, "de tal maneira que o ajustamento de um discurso científico a si mesmo consiste, em última instância, na apropriação dos instrumentos pela teoria" (HENRY, 1997, p. 17). Na sequência, uma observação de Paul Henry merece destaque: "é isto que faz da atividade científica uma prática" (loc. cit.).

\section{Observações a partir da perspectiva dialógica}

De fato, a AD aparece no cenário das ciências humanas questionando a legitimidade da cisão entre reflexão teórica e os encaminhamentos metodológicos, porque recusa os imperativos de 
objetividade e neutralidade tão característicos do pensamento moderno. No vasto campo dos estudos do discurso, passaremos a fazer algumas considerações, inspirando-nos em uma orientação dialógica.

Uma marca desse debate reside no cuidado que se deve conferir à materialidade verbal para que não seja tomada como "dado", a que se atribuiria certa autonomia diante do contexto do qual teria sido "extraído". Essa suposta autonomia produziria o efeito indevido de fazer supor que o tipo de conhecimento proveniente da análise empreendida viria apenas do exame dos enunciados. Dessa forma, a compreensão segundo a qual "cada enunciado é um elo da cadeia muito complexa de outros enunciados" (BAKHTIN, 2011, p. 296) torna-se aqui uma advertência imprescindível, propondo o investimento em formas de restituir, a partir dos enunciados, sua situação de produção.

Os desdobramentos da perspectiva de Bakhtin têm sido apropriados recentemente e tendem, por exemplo, a considerar que as interações entre pesquisador e participantes da pesquisa de campo "constituem-se a partir de um amplo processo de negociação, no qual entram em jogo diferentes interesses e expectativas em relação ao Outro" (VARGENS et al., 2008, p. 158). A compreensão de um processo de pesquisa a partir da perspectiva dialógica insere a negociação de sentidos não apenas no plano do que se diz em situação de pesquisa, mas se desdobra na própria densidade da instituição pesquisa. O diálogo e a negociação de sentidos com o campo já se inicia no momento mesmo de elaboração de objetivos, de escolha dos instrumentos de captação de textos, de articulação de referenciais teóricos, uma vez que todas essas etapas "dependem da tentativa de se entender as necessidades dos sujeitos pesquisados e as suas possíveis demandas, embora muitas vezes não sejam concretamente verbalizadas" (Ibid., p. 161).

A reflexão acerca da pesquisa de campo é desdobramento da perspectiva proposta por Rocha, Sant'Anna e Daher (2004), quando recusam compreender a entrevista como mero instrumento de captação de saberes, mas afirmando seu estatuto de "dispositivo de produção/captação de textos, isto é, um dispositivo que permite retomar/condensar várias situações de enunciação ocorridas em momentos anteriores" (ROCHA; SANT'ANNA; DAHER, 2004, p. 175).

Segundo uma orientação dialógica de pesquisa, não se pode conceber o momento da análise - o ato de compreender os textos - como a produção de algo que não seja igualmente um texto. "Compreende-se 
sempre sob a forma do processo da palavra, reconstruindo-traduzindo o texto do outro" (AMORIM, 2004, p. 48). Essa tradução do texto do outro é também um texto, pois "ao concordar, discordar, completar, interromper, retirar-se, o coenunciador manifesta-se ativamente". Enfim, “compreender é, assim, posicionar-se" (DEUSDARÁ, 2013, p. 44).

\section{Grupo focal: uma breve caracterização contextualizada}

Passaremos agora a uma breve revisão da literatura a respeito do dispositivo de grupo focal, tecendo, na sequência, comentários críticos. Localizados entre observação de campo e entrevistas individuais, os grupos focais têm sido descritos como envolvendo um "bisbilhotar estruturado", de acordo com Powney (1988 apud BARBOUR, 2009), pois estão situados, segundo ele, no continuum entre estrutura e espontaneidade. Segundo Barbour (2009), é justamente a capacidade de injetar alguma estrutura que dá aos grupos focais uma vantagem, além dos vários insights possíveis de serem elucidados por meio da interação com os participantes, no momento em que os dados são gerados. Observe-se que o desejo de se aproximar da "espontaneidade" sugere uma espécie de naturalidade para os fenômenos a serem investigados.

\section{Definição e antecedentes históricos}

A literatura sobre grupos focais evoca alguns debates a respeito de sua definição e terminologia. Dessa forma, os termos "entrevista de grupo", "entrevista de grupo focal", "grupos de discussão" e "discussões de grupo focal" são assumidos como reformulações possíveis e intercambiáveis. A definição de Kitzinger e Barbour (1999 apud BARBOUR, 2009, p. 21) tem obtido maior adesão: "qualquer discussão de grupo pode ser chamada de grupo focal, contanto que o pesquisador esteja ativamente atento e encorajando as interações do grupo".

Observam-se orientações ao pesquisador, para que assuma papel ativo, o qual é compreendido como aquele que estimula a interação, evitando posicionar-se como simples moderador. Esse papel não se resume somente ao momento de aplicação dos grupos focais, como também à elaboração do roteiro de discussão (ou guia de tópicos) e às decisões tomadas com relação à composição do grupo, garantindo que os participantes tenham algo em comum para que a discussão pareça 
apropriada, mas que também apresentem experiências variadas o bastante para que ocorram debates e diferenças de opinião.

As técnicas de grupo focal surgiram em meados dos anos 1940 e tinham como objetivo principal testar as reações às propagandas e transmissões de rádio durante a Segunda Guerra Mundial. Paul Lazarsfeld, Robert Merton e demais colegas da Agência de Pesquisa Social Aplicada da Universidade de Colúmbia foram os principais precursores dessa técnica.

Após a Segunda Guerra Mundial, métodos de grupos focais foram adotados pela pesquisa com emissão de mensagens, marketing e opinião pública. $\mathrm{Na}$ área de marketing, esse método é atualmente bastante difundido, mas diferencia-se de sua aplicação nas Ciências Sociais, pois é comumente utilizado para a geração de dados em relação à percepção do público sobre produtos específicos ou campanhas neste segmento.

\begin{abstract}
Nessa tradição grupos focais são valorizados pela capacidade de fornecer respostas imediatas e, portanto, de antecipar tendências de mercado, em vez de ser por sua capacidade de obter informações detalhadas do tipo geralmente requerido por pesquisadores de serviços de saúde e cientistas sociais (BARBOUR, 2009, p. 30).
\end{abstract}

No final do século passado, a técnica de grupos focais ganhou significativa importância nas Ciências Sociais, quando passou a ser adaptada ao uso na investigação científica como complementar às técnicas quantitativas de análise. Atualmente, a referida técnica é bastante utilizada por pesquisadores da área da Saúde, Psicologia e Ciências Sociais (ARANTES, 2013).

\title{
Fatores considerados relevantes na preparação e realização dos grupos
}

Considerando o lugar conferido aos resultados encontrados nos grupos, Morgan (1997) propõe dividir os grupos focais em três modalidades: i) grupos autorreferentes (utilizados como fonte principal de dados); ii) grupos focais como técnica complementar (quando a intenção é utilizar o grupo como estudo preliminar na avaliação de programas de intervenção e elaboração de questionários e escalas) e, finalmente, iii) grupo focal como proposta multimétodos qualitativos, 
integrando seus resultados aos da observação participante e da entrevista em profundidade. Sem dúvida, a articulação entre a modalidade utilizada, os objetivos da pesquisa, arcabouço teórico mobilizado e os contextos institucionais investigados não podem deixar de ser explicitados na pesquisa, como forma de valorizar o caráter de antecipação ao diálogo que as escolhas do pesquisador em cada uma das etapas possui, seu potencial dialógico.

Descreveremos a seguir reflexões sobre o processo de "coleta de dados" em ambientes cujo contexto é o trabalho e sobre a importância da observação dos seguintes aspectos: clareza dos propósitos de pesquisa e definição de seus objetivos, ambiente físico utilizado, recursos empregados para a realização da pesquisa, recrutamento e seleção de participantes, produção do roteiro do grupo e o respeito aos participantes.

A primeira reflexão versa sobre a clareza dos propósitos e a definição dos objetivos da pesquisa, elementos considerados fundamentais na condução dos grupos pelo moderador para que possa lidar com situações em que sua interferência na adaptação de determinados processos possa ser bem articulada e estar em consonância com os objetivos, para que se mantenha concentrado na produção de dados relevantes ao contexto que se pretende investigar. Essa definição de objetivos também indica caminhos para a elaboração de roteiros de discussão e garante que as questões sirvam como instrumentos para a condução do grupo. No entanto, é preciso que o moderador esteja atento às interações emergentes que podem, aparentemente, não se enquadrar aos objetivos e interações anteriormente imaginadas. Essas interações merecem atenção especial, sobretudo porque podem ser significadas.

O segundo aspecto sugerido - a escolha do ambiente - também deve ser levado em consideração, visto que objetos presentes no ambiente do grupo focal (cartazes, pôsteres, quadros) oferecem sugestões semióticas diversas que podem integrar a interação realizada, produzindo efeitos indesejados como o da intimidação de participantes ou de integração e acolhimento. Se a opção for por um ambiente de trabalho, por exemplo, parte do que talvez se verbalize na situação estabeleça diálogo com essa condição de trabalhador e não apenas com a de participante da pesquisa. Nesses contextos não se pretende buscar a produção de sentidos isenta dessas interferências, mas, sim, como essas construções são definidas a partir da própria identificação desses processos. 
O terceiro fator considerado diz respeito aos recursos monetários para a realização dos grupos focais. Não obstante ser atribuída à técnica de grupos focais a suposta vantagem de ser um método rápido e de baixo custo, Krueger (1993) desconstrói esse "mito" apontando os elementos que podem gerar custos à pesquisa: recrutamento de participantes (telefonemas, anúncios, cartas), local onde a pesquisa será realizada, custos com deslocamento, alimentação, equipamentos eletrônicos, análises, transcrições, entre outros.

O quarto item refere-se à escolha dos participantes, já que essa decisão também, de certo modo, representa uma antecipação das interações que emergirão. Essa tarefa de recrutamento pode demandar muito tempo da pesquisa, uma vez que não é tarefa simples encontrar indivíduos que estejam dispostos a participar, voluntariamente, de uma pesquisa não remunerada. Além disso, a segmentação pode constituir tarefa de difícil realização para os grupos, dependendo dos sentidos que se pretende ver entrar em cena.

Por esse motivo, a decisão sobre a amostra de participantes dos grupos focais deve ser um fator cuidadosamente observado de acordo com os objetivos da pesquisa e dos posicionamentos com os quais se pretender entrar em contato. A literatura disponível aponta a ausência de regras para a composição dos grupos, mas muitos teóricos concordam que os participantes devam ter, pelo menos, uma característica em comum e que tal característica tem de ser o bastante para permitir uma variação suficiente de opiniões e vivências divergentes.

De acordo com a literatura, os grupos também não devem ser nem muito grandes, nem muito pequenos. A pesquisa em questão ateve-se, portanto, a aproximadamente seis participantes por grupo, pois grupos maiores acabaram por limitar a participação de alguns, restringindo as oportunidades de troca de posicionamentos e elaborações, aprofundamento do tema. Além disso, também dificultou os registros. Para se fixar quantos grupos focais conduzir, é comum utilizar-se de três ou quatro grupos e, então, verificar a quantidade e o nível de informações obtidas para a questão em estudo.

No entanto, em nossa prática, percebeu-se que regras não necessitam ser estabelecidas, se as produções de textos forem consideradas suficientes pelo moderador. Essa suficiência depende das pretensões dos pesquisadores e do estudo, mas é admitida quando se julga que já se obteve o conjunto de produções textuais necessário 
para a problematização do objeto e se julga muito provável que novas produções não aparecerão, pois acabam por se tornar repetitivas e circulares (ARANTES, 2013).

O quinto aspecto a ser abordado é a produção do roteiro de discussão. Assim, deve-se pensar nos objetivos de cada questão, antecipando o que provavelmente poderá se tornar um texto dentro dos grupos em interação e, desse modo, formular questões mais gerais ou específicas, dependendo do problema de pesquisa. A ordem em que as questões serão apresentadas ao grupo e os Probes (perguntas que serão utilizadas caso a primeira formulação da questão não seja compreendida ou respondida pelos participantes) também podem interferir na coleta e na produção de textos/dados.

Além disso, a literatura alerta para o fato de que o moderador deve planejar um número tal de questões que não ultrapasse o tempo disponível para a realização dos grupos focais. Com relação a esse ponto, consideramos que não será a quantidade de perguntas feitas em interação que determinará a suficiência ou pertinência dos "dados" produzidos. Sendo assim, o moderador precisa estar atento às diversas formas de produção de textos orais que ganham importância nos contextos de ação e de interlocução inter ou intragrupal.

A formulação das questões deve estar direcionada à escolha dos participantes para o grupo, uma vez que a escolha vocabular ou o uso de socioletos deve ser explicitada de acordo com as previsões imaginadas de recuperação de sentidos que podem ser ativadas ou não pelos participantes, podendo interferir no acesso às opiniões ou entendimentos diversificados.

O uso de questões abstratas ou filosóficas deve ser cuidadoso, bem como questões delicadas sobre valores que podem expor os participantes e constrangê-los na discussão, ou sugerir certo grau de hierarquia, o que parece desejar evidenciar a assimetria constitutiva da situação. Em muitos casos, os valores comunitários podem ser diferentes dos valores individuais, e os sujeitos podem não concordar em expor sua opinião, o que exigirá compromisso ético com o encontro.

O manuseio cuidadoso dos textos produzidos em situação é um processo bastante delicado, pois deve incluir informações, análises e interpretações sobre o contexto, gravações feitas pelos equipamentos, notas de campo e transcrições. Assim, a qualidade das gravações afeta diretamente a qualidade das transcrições, assim como a falta de notas de 
campo afeta as transcrições, pois no momento da atuação do moderador nos grupos focais, este deveria estar concentrado na discussão, e o trabalho de anotação dos textos verbais e não verbais deve ser desenvolvido por um observador que esteja fora da discussão. As informações sobre o contexto auxiliam muito a interpretação dos "dados" e as análises de determinados tipos de comportamento ou interação. Os elementos não verbais podem ser capturados de forma restrita pela filmagem, pois o posicionamento da câmera não antevê onde e o que focalizar durante as discussões.

Finalmente, para abordar o último aspecto supracitado, o respeito aos participantes e ao método interfere na qualidade da pesquisa quando, por exemplo, os participantes não são respeitados ao expor suas opiniões, experiências ou pontos de vista. O método também deve ser respeitado e seus limites devem ser reconhecidos e considerados, pois pode ser apropriado para se obter determinadas informações, mas em outros casos pode demonstrar-se fraco.

\section{Encontros de pesquisa em campo: restituição/invenção de diálogos entre a opção pelo grupo focal e uma perspectiva discursiva}

No item anterior, expusemos reflexões sobre o grupo focal como instrumento de pesquisa. Em nossa exposição, é possível notar que recuperamos nossas considerações em fontes da literatura sobre o tema que não o abordam de uma perspectiva discursiva e também não assumem em seu horizonte de reflexões uma compreensão dialógica da linguagem.

Essas observações preliminares no presente item nos parecem necessárias, antecedendo a articulação que proporemos na sequência. Com elas, gostaríamos de salientar que não há um único método que já possua a resolução para os impasses a serem vivenciados pelo pesquisador no campo. Dito de outro modo, não nos parece ser uma crença factível aquela que pretende aprimorar um determinado método a ponto de almejar a situação em que tal instrumento esteja absolutamente livre de interferências, podendo este então ser apenas aplicado. Conceber o exercício da pesquisa desse modo nos aproxima do que diz Guattari, quando considera os conceitos como "ferramentas, e as teorias o equivalente de caixas contendo-as - sua potência não podendo exceder os serviços prestados em campos delimitados" (GUATTARI, 2007, p. 33). Do mesmo modo, estamos autorizados a considerar que a potência 
de certo instrumento de pesquisa residiria justamente na possibilidade de "prestar serviços" a campos delimitados, favorecer processos de intervenção em circunstâncias concretas de produção de sentido e vida.

Dessa constatação da incompletude que estamos atribuindo a todos os métodos, parece ser possível também extrair algo que remeteria a certo grau de liberdade do pesquisador. Se não há método já integralmente aprimorado - a ponto de poder ser tão somente aplicado em diferentes circunstâncias -, isso também significa assumir que todos os métodos possuem vantagens e desvantagens. Sendo assim, a atenção conferida aos objetivos da pesquisa é fator determinante no direcionamento das escolhas metodológicas e técnicas para a realização de cada estudo em questão (ARANTES, 2013).

Diante do imperativo de cientificidade, Foucault propõe uma insurreição "contra os efeitos centralizadores de poder que são vinculados à instituição e ao funcionamento de um discurso científico organizado no interior de uma sociedade como a nossa" (FOUCAULT, 2002, p. 14). Nesse cenário, sua genealogia seria "uma espécie de empreendimento para desassujeitar os saberes históricos e torná-los livres". Assim, no lugar de reivindicar um estatuto de cientificidade, o desejo é tornar esses saberes "capazes de oposição e de luta contra a coerção de um discurso teórico unitário, formal, científico" (Ibid., p. 15).

Com efeito, nesses termos, produzir conhecimento é, em certa medida, participar de uma luta, que pode se atualizar tanto nas reivindicações por hierarquização de saberes, por cumprimento dos rituais institucionalizados no âmbito de uma disciplina de um campo, quanto na liberação dos saberes dessas grades centralizadoras, cujos resultados estão, de algum modo, previstos em suas operações. Afirma-se, com isso, uma concepção de fazer teórico como prática, institucionalmente situada, de produção de saber.

Aliás, trata-se de um dos aspectos fundadores do campo dos estudos do discurso à crítica aos métodos utilizados pela análise de conteúdo. Já no texto de 1969, Pêcheux apontava que toda teoria pressupõe igualmente a (re)invenção de seus instrumentos, "de tal maneira que o ajustamento de um discurso científico a si mesmo consiste, em última instância, na apropriação dos instrumentos pela teoria". Na sequência, uma observação de Paul Henry merece destaque: "é isto que faz da atividade científica uma prática” (HENRY, 1997, p. 17). 
A esse respeito, as diferentes avaliações sobre a ausência de roteiros metodológicos fixos configuram-se como pistas importantes para modos distintos de conceber o exercício investigativo em Ciências Sociais. Articulando essas duas ordens de preocupações, o propósito de nossa reflexão é colocar em questão o percurso metodológico como uma invenção ${ }^{2}$, cuja legitimidade não se sustenta na repetição de roteiros prévios, mas na explicitação dos encaminhamentos adotados e de seu diálogo permanente com os objetivos propostos pelo trabalho de investigação. Para isso, opera-se uma torção do rigor científico, que observa a produção de conhecimento como prática reflexiva. Nesse sentido, parece-nos que tal prática pode também ser constituída em contextos mais gerais de pesquisas qualitativas, justificados a seguir.

No caso específico das pesquisas de caráter qualitativo, em que a replicação e a comprovação da aquisição dos dados são mais difíceis, cabe ao pesquisador relatar os objetivos do estudo e os procedimentos utilizados para alcançá-los; mais do que isso, ser autocrítico com relação às escolhas efetuadas e à aplicação de métodos, reconhecendo os limites e dificuldades que as escolhas podem oferecer à pesquisa. Sendo assim, é fundamental que o pesquisador explicite detalhadamente, e com transparência, as dificuldades encontradas e os fatos considerados (ou não considerados) ao longo da aplicação e do desenvolvimento da pesquisa (ARANTES, 2013).

Se a perspectiva discursiva emerge no cenário das ciências humanas evidenciando a dimensão política implicada e se destacamos anteriormente nosso distanciamento em relação à designação "dados" atribuída aos materiais submetidos à análise, trata-se de uma opção que nos parece produtiva para a trajetória de reflexões que pretendemos empreender, rejeitando a possibilidade de supor qualquer autonomia dos enunciados "coletados" das situações de enunciações das quais emergem e às quais remetem indissoluvelmente. O primeiro deles encontra-se marcado no desejo de relativizar a designação "dados" conferida à materialidade verbal com a qual lidamos em nossas pesquisas como analistas do discurso. Isso se deve ao fato de a referida designação sugerir, entre outros aspectos, certa autonomia dos "dados" no contexto do qual teriam sido "extraídos", fazendo supor que o tipo de conhecimento proveniente da análise empreendida viria apenas do exame dos enunciados.

\footnotetext{
${ }^{2}$ Termo inspirado na discussão de Foucault sobre Nietzsche (2005).
} 
Arriscaríamos dizer que, entre os métodos à disposição dos pesquisadores, diversos deles podem apresentar maior ou menor grau de aderência a uma perspectiva dialógica. A explicitação dos critérios utilizados para a opção por um ou por outro instrumento metodológico pode viabilizar análise das implicações do pesquisador com as redes de diálogo em funcionamento no processo de pesquisa. Para isso, é preciso sustentar as dúvidas, as inseguranças, procurando recuperar os valores, as relações, os desejos em jogo, quando se opta por um determinado caminho de pesquisa.

\section{Orientação discursiva e a possibilidade de acolhimento das inferências}

Elaboramos a seguir um diálogo que pretende articular as considerações que expusemos a respeito do instrumento de grupo focal com as discussões acerca de uma concepção discursiva da prática de pesquisa. Para o encontro desses dois eixos que atravessaram este texto, apresentaremos alguns encaminhamentos que articulam delimitação do tema, explicitação dos objetivos, trechos de transcrição das interações realizadas por Arantes (2013).

As práticas de análise dos textos obtidos em situação de pesquisa de campo podem proporcionar-nos o acesso a sentidos que ganham consistência no grupo, a partir da observação de produção de consenso ou de embates. Trata-se de elemento interessante para se observar as forças atuantes em situação e em contextos determinados, principalmente as forças emergentes em contextos de trabalho.

Apresentaremos alguns aspectos da pesquisa ${ }^{3}$ realizada pelo método de grupo focal para a investigação exploratória acerca das práticas de leitura de jornais populares em dois contextos sociodiscursivos divergentes: o alemão e o brasileiro.

Merece destaque nessa elaboração do tema de pesquisa um conjunto de aspectos que já figuram como elementos que determinarão as escolhas do pesquisador. Considerando que o princípio dialógico de que toda compreensão se realiza necessariamente pela elaboração de outro texto, a explicitação das escolhas e das premissas que a sustentam se configura como parte importante da prática de pesquisa como integrante de um diálogo e não apenas captação de "dados".

\footnotetext{
${ }^{3}$ Para acesso ao texto completo, ver Arantes (2013).
} 
Um primeiro aspecto reside na opção por práticas de leitura. À primeira vista, pesquisas sobre as práticas de leitura teriam muito de seu vínculo remetendo à instituição escolar: "leitura é atividade que se realiza na escola", pode-se pensar. Muito do contato cotidiano que se tem com textos deixa de ser compreendido como leitura. Não é pouco recorrente o lamento acerca da escassa frequência com que jovens e crianças leriam. Ignora-se todo o tipo de contato com textos diversos, privilegiando em tal lamento a leitura de livros - aqueles que, na verdade, os jovens já não leem mais, suporiam.

Outro aspecto a ser assumido como importante no conjunto de diálogo em jogo no processo de elaboração da pesquisa remete à proposta de trabalhar com jornais populares. Em certos contextos, entre eles o acadêmico, os referidos periódicos são frequentemente tomados como pouco "confiáveis". Essa crítica faria supor imediatamente que haveria outros mais confiáveis, o que igualmente não deixará de ser questionado por diversos outros atores sociais, a exemplo das manifestações sociais em que uma dada emissora foi intensamente mencionada como não confiável.

Nesse contexto, a pesquisadora registra já saber que a decisão por procurar leitores de jornais populares e de grande tiragem, como Bild Zeitung (Stuttgart, Alemanha) ou o Super Notícia (Belo Horizonte, Brasil), poderia ser recebida de diferentes modos, por ser capaz de antecipar que, em certos contextos, atribui-se conotação pejorativa à sua leitura, o que poderá não ocorrer em outros contextos. A opção por um contexto ou por outro precisa ser explicitada e já antecipa certo tipo de texto a ser produzido.

Dessa forma, esses e outros diálogos integram os encaminhamentos de uma pesquisa cujo objetivo principal foi buscar compreender os universos de preferências e gostos dos leitores, o que se configura como etapa complementar às análises linguístico-discursivas do material linguístico, isto é, jornais do segmento popular como o Bild Zeitung e o jornal Super Notícia. Privilegiaremos aqui a coleta de dados realizada apenas acerca do jornal popular brasileiro.

Partindo de uma análise exploratória de determinado tema, os participantes de um grupo focal podem, por exemplo, levar em consideração em suas deliberações fatores que os pesquisadores não haviam antecipado. Esse tipo de aspecto, segundo Barbour (2009, p. 57), "pode salientar a relevância para o pesquisador de explicações alternativas de percepções ou comportamentos - ou mesmo de novos 
paradigmas teóricos, cuja consideração durante a análise pode vir a ser útil", tais como defesa por posicionamentos relacionados à posição hierárquica que ocupam, prescrições relativas a comportamentos no ambiente de trabalho, entre outros.

Uma das vantagens da interação entre os participantes permitida pelo grupo é a aproximação das pessoas que são pouco acessíveis ou potencialmente relutantes em se envolver com entrevistas individuais, pois dificilmente a posição de alguém será definida sem correlacioná-la com outras posições. Considerando que "a expressão do enunciado nunca pode ser entendida e explicada até o fim levando-se em conta apenas o seu conteúdo centrado no objeto e no sentido" (BAKHTIN, 2011, p. 297), argumentamos que os grupos focais podem permitir aos participantes a oportunidade de administrar, simultaneamente, seus posicionamentos individuais e desenvolver uma representação coletiva para o pesquisador mediante a construção de significados e de seus impactos na ação.

Parte da tarefa do pesquisador-moderador é "problematizar" ou trazer uma perspectiva crítica a respeito das afirmações produzidas ou levantadas por outros meios, em vez de simplesmente tomá-las como dadas e se debruçar sobre elas como se fossem conteúdos a serem desvelados. Dessa forma, os grupos focais quase inevitavelmente encorajam essa posição questionadora, oferecendo condições para deslocamentos, para se pensar de forma diferente (ARANTES, 2013).

Além disso, a abordagem permite capturar respostas a eventos enquanto estes se desenrolam, exigindo certa atenção aos imprevistos de uma dada situação. Wilkinson (1999) sugere que as discussões de grupos focais podem oferecer uma abertura para os processos que de outro modo permaneceriam ocultos e são difíceis de penetrar, pois durante as seções de grupo focal "um senso coletivo é estabelecido, os significados são negociados e as identidades elaboradas pelos processos de interação social entre as pessoas" (WILKINSON, 1999 apud BARBOUR, 2009, p. 49).

Em Arantes (2013), considerou-se como elemento comum entre os participantes a condição de leitores assíduos do jornal Super Notícia. Esse elemento também foi levado em consideração na seleção dos participantes para a entrevista com os leitores do Bild Zeitung na Alemanha. Não interessava à pesquisa homogeneizar tanto o grupo, já que seu objetivo era exploratório e não se baseou em aspectos socioculturais e econômicos para análises intergrupais ou cruzamento de variáveis. 
Para tanto, interessou à pesquisa a busca por grupos heterogêneos, e, no caso das entrevistas realizadas na Alemanha, aleatórios, considerando os traços comumente assumidos por pesquisas de campo: classe socioeconômica, gênero, escolaridade, estado civil, idade e local de residência.

Definido o elemento comum que os participantes deveriam apresentar como pré-requisito, passou-se a investigar onde tais participantes poderiam ser recrutados para que se obtivesse uma amostra heterogênea de leitores dos jornais considerados, pois, segundo Gatti (2005, p. 18), "ligado aos objetivos, é preciso considerar o que se sabe sobre o conjunto social visado, uma vez que algum traço comum entre os participantes deverá existir, estando isso na base do trabalho com o grupo focal". Assim, optamos pelo recrutamento de participantes em locais públicos que os leitores frequentariam; por hipótese: feiras livres, pontos de ônibus, parques, praças.

A definição da característica comum entre os participantes dos grupos deve também levar em conta que "os participantes devem ter alguma vivência com o tema a ser discutido, de tal modo que suas experiências possam trazer elementos ancorados em suas experiências cotidianas" (Ibid., p. 5). Por esse motivo escolheram-se, preferencialmente, leitores assíduos dos jornais que teriam vivenciado mais experiências pelo contato com o jornal. Assiduidade foi entendida como frequência de leitura semanal igual ou maior que três dias.

Com relação ao número de participantes, a literatura recomenda que os grupos não devem ser nem muito grandes, nem muito pequenos. Ativemo-nos, portanto, à recomendação de seis a dez participantes em cada grupo, pois grupos maiores acabariam por limitar a participação, as oportunidades de troca de ideias e elaborações, o aprofundamento do tema e também os registros, sobretudo porque dispomos de apenas uma hora para a realização do grupo, já que esse intervalo de tempo correspondeu à pausa para o almoço dos funcionários de uma empresa.

$\mathrm{O}$ número de grupos focais realizados também dependeu do planejamento, dos objetivos da pesquisa, do tempo disponível e, principalmente, da saturação da produção de dados, pois percebemos que, a partir do terceiro grupo focal aplicado, as informações e dados obtidos se repetiam e não havia mais produção de dados novos, assim como observado por Gatti (2005, p. 23): 
Para fixar quantos grupos focais conduzir, é comum utilizar como procedimento a realização de três ou quatro grupos e, então, verificar a quantidade e o nível de informações obtidas para a questão em estudo. Se as informações forem consideradas suficientes, não se compõem outros grupos. Essa suficiência depende das pretensões dos pesquisadores e do estudo, mas ela é admitida quando se julga que já se obteve o conjunto de ideias necessário para a compreensão do problema e se julga muito provável que novas ideias não aparecerão.

Como não pudemos prever que a saturação de dados apareceria já no terceiro grupo focal, foi planejada a realização de quatro grupos inicialmente e depois observada a necessidade de não se realizarem mais aplicações.

Antes da realização das discussões nos quatro grupos focais (quatro grupos no Brasil e quatro na Alemanha) estabelecidos, foi criado um Grupo Focal, em cada país, como projeto-piloto, a fim de testarmos a efetividade do questionário para a produção de dados em tempo determinado, da dinâmica do grupo, da condução do moderador nas discussões e, por fim, testar o funcionamento dos aparelhos técnicos para garantir sua utilização posteriormente, nas análises.

Tal processo de interação no Grupo Focal pode ser ilustrado a partir do excerto a seguir, retirado das discussões de grupo realizado com leitores do jornal Super Notícia, no intervalo de almoço (uma hora de duração), em uma empresa na região metropolitana de Belo Horizonte, Minas Gerais:

A:[0:15:54] Teve uma notícia há um tempo atrás aí na época que eu estava estudando, em 2008. Que aconteceu que o Super noticiou. Só que era próximo, é, foi uma, um assassinato próximo à escola onde eu estudava, que era o SESI, né?! Só que no Super eles noticiaram que era num bairro próximo ao nosso bairro, em uma outra escola, não o SESI.

J: [0:16:16] Ah, entendi!

A: [0:16:17] Foi de frente pra o SESI, mas colocaram a escola "Arão Reis" e o bairro onde era a escola [CE: você tá falando daquele do SESI lá?] É. Então acho que foi assim, num sei, acho que foi proposital. 
$\mathrm{J}:[0: 16: 30]$ Você acha que foi proposital ?[A: lógico!] Por quê ? A:[0:16:31] Eu acho que a empresa SESI tem, deve ter uma ligação ou então uma força maior de desvincular o nome dela ao [C: SESI é mais indústria] ao acontecido. Então foi, pra gente foi [L: então você achou que eles devem ter feito de propósito pra não expor o nome do SESI?] É. Não expor o nome do SESI que é bem mais forte do que o "Arão Reis" que é uma escola pública. [L: será?] [A: e você acha que alguém vai querer estudar numa escola onde aconteceu um assassinato?] [L: Hum, entendi].

(Trecho de transcrição de grupo focal, 1 de outubro de 2011, Belo Horizonte. ARANTES, 2013)

Essa interação entre os participantes permite que possam reconhecer nos outros partes de si mesmos previamente ocultas e, assim, tenham tempo e oportunidade para refletir sobre suas próprias experiências, identificações e opiniões a partir do confronto de opiniões entre os demais membros do grupo. Trata-se de um processo produtivo viabilizado não por uma reflexão posterior sobre os resultados atingidos, mas, sim, por algo viabilizado na própria situação de pesquisa.

Atento a isso, o pesquisador pode contribuir para fazer ver um potencial de intervenção latente ao próprio processo de pesquisa, anterior e relativamente independente dos resultados pretendidos pelos objetivos originalmente estabelecidos. O que se ilustra aqui é o fato de uma pesquisa ter seu valor compreendido pelos resultados que oferece após suas análises, mas, também, de outra parte, por viabilizar na própria situação de pesquisa a elaboração de hipóteses, a busca de alianças, a tentativa de convencimento.

É preciso que o moderador esteja atento às interações emergentes que podem, aparentemente, não se enquadrar aos objetivos e interações anteriormente imaginados. Essas interações merecem atenção especial, sobretudo porque podem ser significadas.

\section{Em direção a uma cartografia das práticas de linguagem}

Neste artigo, centramos nossas reflexões na ideia de que a legitimidade do percurso metodológico não se sustenta na repetição de roteiros prévios, mas na explicitação dos encaminhamentos adotados e de seu diálogo permanente com os objetivos propostos pelo trabalho de 
investigação. Para isso, sugerimos considerar a possibilidade de operarse uma torção do rigor científico, que passa a observar a produção de conhecimento como prática reflexiva. Assim, parece-nos que tal prática pode também ser constituída em contextos mais gerais de pesquisas qualitativas.

A orientação reiterada até aqui de explicitação das etapas metodológicas - não apenas como registro dos impasses encontrados, mas fundamentalmente como a preocupação de caracterizar que as interações que ocorrerão em situação de pesquisa constituem apenas uma pequena parte de um diálogo que atravessa todo o percurso da pesquisa - tem nos aproximado de iniciativas no campo da psicologia social, em especial das reflexões sobre pesquisa-intervenção (AGUIAR; ROCHA, 2007; ROCHA; AGUIAR, 2003) e o método da cartografia (PASSOS et al., 2009, 2014; PASSOS; KASTRUP, 2013).

Essas iniciativas afastam qualquer projeto de imparcialidade do pesquisador. Suas reflexões se dirigem justamente no sentido de potencializar as interferências e não tratá-las como algo a ser evitado, "considerando que essa interferência não se constitui em uma dificuldade própria às pesquisas sociais, em uma subjetividade a ser superada ou justificada no tratamento dos dados" (ROCHA; AGUIAR, 2003, p. 76).

Se há um projeto compartilhado, uma espécie de empreendimento comum, no sentido de investir na análise dos processos, parece-nos interessante buscar compreender que entradas específicas são favorecidas pelas especialidades. Longe de pretender investir na antiquada e estéril "demarcação de território" - lamentavelmente, atitude ainda insistente em alguns atores do universo institucional acadêmico -, indicamos uma contribuição da especialidade em estudos linguísticos.

A especialidade do linguista residiria em sua preocupação com o desenvolvimento de práticas de pesquisa que permitem operar com a materialidade verbal, considerando o seguinte aspecto fundante da palavra ao desempenhar um papel de "regulação/construção do vasto leque de relações que se estabelecem entre os homens: relações de dominação, de enfrentamento, de definição de identidades, de produção de diferentes modos de subjetivação" (ROCHA, 2014, 263).

Portanto, todo pesquisador está irremediavelmente implicado no tipo de conhecimento produzido, com os consentimentos que sua prática sugere. "Estar implicado (realizar ou aceitar a análise de minhas próprias implicações) é, ao fim de tudo, admitir que eu sou objetivado por aquilo que pretendo objetivar" (AGUIAR; ROCHA, 2007, p. 656). 


\section{Referências}

AGUIAR, K.; ROCHA, M. L. Micropolítica e o exercício da pesquisaintervenção: referenciais e dispositivos em análise. Psicologia - Ciência e Profissão, v. 27, p. 648-663, 2007.

AMORIM, M. O pesquisador e seu outro: Bakhtin nas ciências humanas. São Paulo: Musa, 2004.

ARANTES, P. O jornal popular brasileiro e o Boulevardzeitung alemão: análise do discurso jornalístico em produção e em recepção. 2013. Tese (Doutorado em Estudos da Linguagem) - Faculdade de Letras da Universidade Federal de Minas Gerais, 2013.

BAKHTIN, M. Estética da criação verbal. Trad. (a partir do francês) Maria Emantina Galvão. São Paulo: Martins Fontes, 2011.

BARBOUR, R. Grupos focais. Porto Alegre: Bookman; Artmed, 2009.

DEUSDARÁ, B. Pragmática e discurso: a noção de texto em questão. Desenredo, Passo Fundo, v. 9, n. 2, p. 340-357, 2013.

FOUCAULT, M. Microfisica do poder. Trad. e org. de Roberto Machado. Rio de Janeiro: Graal, 1998.

FOUCAULT, M. Em defesa da sociedade. Trad. Maria Ermantina Galvão. São Paulo: Martins Fontes, 2002.

FOUCAULT, M. Vigiar e punir: nascimento das prisões. 29. ed. Trad. Raquel Ramalhete. Petrópolis: Vozes, 2004a.

FOUCAULT, M. A Arqueologia do saber. Trad. Luiz Felipe Baeta Neves. Rio de Janeiro: Forense Universitária, 2004b.

FOUCAULT, M. A Verdade e as formas jurídicas. Trad. Roberto Machado e Eduardo Morais. Rio de Janeiro: Nau, 2005a.

FOUCAULT, M. Ditos e escritos II: arqueologia das ciências e história dos sistemas de pensamento. Trad. de Elisa Monteiro. Rio de Janeiro: Forense Universitária, 2005b.

FOUCAULT, M. O poder psiquiátrico: curso dado no Collège de France. São Paulo: Martins Fontes, 2006.

GATTI, B. A. Grupo focal na pesquisa em ciências sociais e humanas. Brasília: Líber Livro, 2005. (Pesquisa em Educação, v. 10). 
GUATTARI, F. 1985 - Microfísica dos poderes e Micropolítica dos desejos. In: QUEIROZ, A.; CRUZ, N. V. (Org.). Foucault hoje? Rio de Janeiro: 7Letras, 2007. p. 33-41.

HENRY, P. Os fundamentos teóricos da "análise automática do discurso" de Michel Pêcheux (1969). In: GADET, F.; HAK, T. (Org.). Por uma análise automática do discurso: uma introdução à obra de Michel Pêcheux. Trad. Bethania S. Mariani et al. Campinas: Unicamp, 1997.

KRUEGER, R. A. Quality control in focus group research. In: MORGAN, D. L. (Org.). Successful Focus Groups: advancing the state of the art. Newbury Park: Sage, 1993. https://doi.org/10.4135/9781483349008.n5.

LABOV, W. Padrões sociolinguísticos. São Paulo: Parábola, 2008.

MARIANI, B.; MEDEIROS, V. Disciplinarização dos estudos em Análise do Discurso. Gragoatá, Niterói, n. 34, p. 15-25, jan.-jun. 2013.

MORGAN, D. L. Focus groups as qualitative research. London: Sage, 1997. https://doi.org/10.4135/9781412984287.

PASSOS, E.; KASTRUP, V. Sobre a validação da pesquisa cartográfica: acesso à experiência, consistência e produção de efeitos. Fractal, v. 25, n. 2, p. 391-414, maio-ago. 2013.

ROCHA, D. Representar e intervir: linguagem, prática discursiva e performatividade. Linguagem em (Dis)curso, v. 14, p. 619-632, 2014.

ROCHA, D.; SANT’ANNA, V. L. A.; DAHER, M. C. F. G. A entrevista em situação de pesquisa acadêmica: reflexões numa perspectiva discursiva. Polifonia, Mato Grosso, v. 8, p. 161-180, 2004.

WILKINSON, S. How useful are focus groups in feminist research? In: BARBOUR, R. S.; KITZINGER, J. (Ed.). Developing focus group research: politics, theory and practice. London: Sage, 1999. p. 64-78. https://doi.org/10.4135/9781849208857.n5. 